\title{
Towards developing an idealised city model with realistic aerodynamic features
}

\author{
E. Reda ${ }^{1,2}$, R. Zulkifli' ${ }^{1}$ and Z. Harun ${ }^{1}$ \\ ${ }^{1}$ Faculty of Engineering and Built Environment, Universiti Kebangsaan Malaysia, \\ UKM Bangi, 43600, Selangor, Malaysia \\ ${ }^{2}$ Department of Mechanical Engineering, Alexandria University, Alexandria, Egypt \\ *Email: zambri@ukm.edu.my \\ Phone: +603 8912 6518; Fax: +603-8925-9659
}

\begin{abstract}
Many concerns related to natural ventilation in urban areas have been deduced from experimental or computational fluid dynamics simulations on idealised models. However, it is not definite that the flow through these idealised models presents similar characteristics to actual urban areas. The objective of this research is to suggest an approach to close the gap between idealised models and genuine cities; i.e., predict actual urban flow characteristics from the ready data of idealised models. The flow was simulated by large-eddy simulation through both the actual city model and a group of idealised models of different structures but the same average dimensions and buildingpacking-density as the actual city. The numerical setup was validated by comparison with wind tunnel measurements from the literature. It was found that an equivalent to the average velocity profile throughout an idealised model can be achieved by a mix of the "five-point spatial average" and the "four-point spatial average". The vertical profiles of mean and turbulent windward velocities of the idealised models manifest a general similarity to those of the actual model. On the other hand, the cross-wind and wall-normal components show large discrepancies. In all cases, the idealised models exhibit very narrow atmospheric surface layer heights compared to the actual model. IM-RAN (which represents a structure of semi-random configuration) displayed the closest results to the actual model but condensed in half the actual model surface layer height. A correction formula was devised to close the gap between the two models. The results confirm the ability to utilise idealised models to deliver recommendations regarding urban environment planning; though, attention should be paid to the selection of the idealised model and corrections may be needed.
\end{abstract}

Keywords: CFD, LES, Air flow, Actual city, Idealised model, Uneven building layout

\section{INTRODUCTION}

Ventilation quality is a major parameter that modern city planners should be concerned with. Poor ventilation often leads to temperature rise, pollutant concentration, and high loads on air conditioning systems, which in turn causes more pollutant emission and further temperature increase. Along with the persisting attempts to reduce the heat release from burning fossil fuels either by improving the efficiency of industrial equipment [1] or developing clean energy sources [2], scientific research targets planning modern cities of enhanced natural ventilation potentials and minimal solar absorption [3]. In addition to natural ventilation, the study of atmospheric flow through cities is important to evaluate 
the stresses [4] and vortex-induced vibrations [5] on buildings and structures due to turbulence coherent structures [6]. As computer capabilities improve, computational fluid dynamics (CFD) becomes more popular with its cost effectiveness and ability to impose a wide variety of conditions. CFD simulations of flow through urban areas use both Reynolds-Averaged Navier Stokes (RANS) and Large Eddy Simulation (LES) models with the latter being capable of simulating turbulent parameters and hence offering more accurate information on heat dissipation and pollutant dispersion. The CFD simulation of wind flow through urban areas is held by one of two approaches; simulation of flow through idealised urban areas and simulation of flow through actual (genuine) urban areas. In the first approach, the idealised structure composes a single or array of simple blocks arranged evenly or unevenly. Many researchers [7-13] adapted this approach as it provides general information about the flow, with high precision and at low computational cost, besides the availability of much experimental data in the literature for validation. However, results obtained by this method are mainly qualitative in nature as long as in reality, actual cities usually contain buildings of almost random geometries and arrangements that greatly differ from the idealised ones. Although some authors [14] have already studied the effect of variability of building height and the arrangement of structure with respect to the flow, no one, to the best knowledge of the authors, has compared the flow structure in such variable height models with genuine cities with similar dimensions.

In the second approach, an actual city or part of it is considered in the simulation. Examples of the application of this approach include simulation of the air flow and heat transfer at three different locations in Kyoto, Japan, of different vegetation levels [15], simulation of the flow through the Centre of Metropolitan Tokyo, Japan, with building shapes reproduced by graphic information system (GIS) [16], simulation of the flow and dispersion in DAPPLE site in Central London, UK, [17], simulation of the pollutant dispersion in downtown of Montreal, Canada, [18], holding a 24-hour simulation of the wind speed, temperature and pollutant concentration fields in the downtown of Macau, China, [19], by using a couple between mesoscale and microscale modelling to simulate the transport and dispersion within Oklahoma City, USA, [20], calculating the wind speed, temperature, and carbon monoxide concentration fields over 24 hours in a district in Beijing, China, [21] and simulating the wind flow through Kuala Lumpur City Centre [22]. This actual city simulation approach gives accurate information about flow through the considered urban areas that help in their future architectural development. Nevertheless, the results obtained lack generality and cannot be applied to any other urban area. In considering the ventilation quality, a city planner has two choices; (1) undertaking a complete simulation for the city which is still in the planning phase, or (2) relying upon recommendations based on idealised models and hence compromising accuracy. The target of the present research is to build a link between the idealised and actual urban area CFD simulations; i.e., devise an idealised urban model able to mimic the mean and turbulent parameters of atmospheric flow through actual cities. This is supposed to help standardising the city planning. In other words, simulating the flow within different configurations of this idealised model and summarising the results in a tabular form could help city planners make initial assumptions regarding the ventilation quality. In this research, wind flow will be simulated in one actual urban area and a group of statistically similar idealised models of different geometries. The comparison between the models will suggest which idealised model better depicts the actual city flow details. The urban area considered in this research is the Kuala Lumpur City Centre (KLCC), in Malaysia. 


\section{METHODS AND MATERIALS}

\section{Geometrical Models \\ Geometrical Model Setup}

The actual model (AM) was generated by using a combination between Google Earth ${ }^{\circledR}$ built-in models and the SketchUp ${ }^{\circledR}$ drawing tool. SketchUp was used to import Google Earth building models and modify them. They are imported automatically in their correct geographic locations relative to each other. Models which are not avilable on Google Earth library were drawn manually by authors such that all buildings higher than $11 \mathrm{~m}$ within 1800-m diameter circle were included in the simulation. The origin of the axes was set at location $\left(3^{\circ} 9^{\prime} 10.83^{\prime \prime} \mathrm{N}, 101^{\circ} 42^{\prime} 40.49^{\prime \prime} \mathrm{E}\right)$ and the $x$ and $y$ directions were taken towards the windward and cross-wind directions as will be discussed in Section "Case Studies". The z-direction is the ground-normal.

\section{Idealising KLCC}

The building-packing-density (built to total plane area ratio) was obtained by image processing of the plan view of AM using the ImageJ 1.48 image processing software. While the average building dimensions were obtained by exporting every building in AM separately to a Stereolithography (STL) file which was later on handled by Scilab ${ }^{\circledR}$ to get building length, width and height. The building length and width were defined as the dimensions in the windward and cross-wind directions, respectively. In the averaging process, complex buildings (comprising two or more buildings) were exploded to their basic elements. The total number of buildings was 82 . The average height of buildings in $\mathrm{AM}$ (and hence the height of the buildings in IMs) was $\mathrm{H}=122 \mathrm{~m}$.

\section{Idealised Models}

A group of idealised models were considered in the study. These specific designs were selected mainly due to their wide use in the literature as idealised urban models [23-25]. All models were statically similar to AM; i.e., built with dimensions equal to the average dimensions of buildings in AM and with the same building-packing-density. This IMs group contains five models; IM-SQuare (IM-SQ), IM-Diamond (IM-D), IM-STaGgered (IM-STG), IM-UnEven (IM-UE), and IM-RANdom (IM-RAN) as shown in Figure 1. IM-UE is a version of the IM-STG with one row of buildings $20 \%$ higher than the average and the second row 20\% lower than it (based on statistical analysis of building heights in KLCC, $45 \%$ of the building heights lie within this range). IM-RAN is another version of IM-STG with the basic four blocks of the repeating unit (B11, B12, B21, \& B22) having undergone three modifications:

1. B11 and B22 are 20\% larger in length and width while B12 and B21 are $20 \%$ smaller in length and width than the average dimensions.

2. B12 and B21 are moved to the middle of the windward span between B11 and B22.

3. $\mathrm{B} 11$ and $\mathrm{B} 21$ are $20 \%$ higher whereas $\mathrm{B} 12$ and $\mathrm{B} 22$ are $20 \%$ lower than the average height $\mathrm{H}$.

The origin of the axes was set at the centre of the ground plane and the $x, y$ and $z$ direction were taken as the streamwise, spanwise, and wall-normal directions, respectively. All models were completely drawn by SketchUp. As mentioned in Section "Boundary Conditions", the inlet, outlet, and lateral boundaries were assigned periodic conditions which allow confining the flow domain to only single repeating unit of the building array as marked in Figure 1. Table 1 summarises the dimensions of AM and IMs. 
All models were exported to STL files which can be readily handled by OpenFOAM, the CFD package used.

Table 1. Average dimensions of buildings in AM and IMs.

\begin{tabular}{lcccc} 
& Length $(\mathrm{m})$ & Width $(\mathrm{m})$ & Height $(\mathrm{m})$ & Building-packing-density (\%) \\
\hline AM & 68.5 & 65.2 & 122 & 22.06 \\
$\mathrm{IMs}$ & 67 & 67 & 122 & 22.06 \\
\hline
\end{tabular}

\section{Mathematical Model}

\section{Governing equations}

The LES is getting increasing popularity $[9,10,20,21,26]$ as an urban environment flow simulation model. The filtered continuity and momentum equations are listed below:

$$
\begin{gathered}
\frac{\partial \bar{u}_{i}}{\partial x_{i}}=0 \\
\frac{\partial \bar{u}_{i}}{\partial t}+\bar{u}_{j} \frac{\partial \bar{u}_{i}}{\partial x_{j}}=-\frac{1}{\rho} \frac{\partial \bar{p}}{\partial x_{i}}+v \frac{\partial^{2} \bar{u}_{i}}{\partial x_{j} \partial x_{j}}+\frac{\partial \tau_{i j}}{\partial x_{j}}
\end{gathered}
$$

In the present study, air was considered to be isothermal and incompressible [27] since the urban canopy lies in the bottom part of the atmospheric boundary layer (ABL). The temperature was assumed to be constant and hence the fluid properties. In the above equations; the variables with overbars denote resolved scale quantities, $\bar{u}_{i}$ is the resolvedscale velocity component in the $x_{i}$ direction, $\bar{p}$ is the resolved scale pressure, $\rho$ is the fluid density, $v$ is the kinematic viscosity, and $\tau_{i j}$ is the subgrid stress. The subgrid stress was obtained by the dynamic Lagrangian model $[21,26]$. The details of the model can be found in [28].

\section{Boundary conditions}

The inlet and outlet boundaries were assigned periodic conditions [7, 9, 12, 26]. This could be realised as passing the flow over an infinite rack of the simulated geometry. In this case, the flow needs to be forced by a fixed value velocity at the top boundary [12] as was utilised here. The lateral boundaries were assigned periodic conditions as well [9, $12,26,29]$. For both actual and idealised models, the ground and building walls were assigned a no-slip condition and wall functions were used to calculate the turbulent kinetic energy at the wall nearest grid point $[30,31]$. The surface roughness height $(z 0)$ was taken as $0.1 \times 11 \mathrm{~m}$ in all models [32].

\section{Computational domain and Mesh Generation}

The design of the computational domain in all models complied with the COST Action 732 [33]. For AM, knowing the average building height is $122 \mathrm{~m}$, the maximum height is $451.9 \mathrm{~m}$ and the plan area of the building block is $1670 \times 1500 \mathrm{~m}^{2}$, the domain height was extended to $1500 \mathrm{~m}$ above ground level and its plan area was set to $1800 \times 1650 \mathrm{~m}^{2}$. For IMs, one repeating unit was only considered in the simulation which is a benefit of the use of periodic boundary conditions [34]. In all IMs, the domain height was set to 1500 $\mathrm{m}$. All models were introduced to OpenFOAM in STL format and the mesh was generated using the snappyHexMesh tool. Two meshes were used for AM for the sake of grid 
dependency analysis; AM and AM-Fine (AMF) which is $\sim 60 \%$ more cells than AM. Table 2 details the number of cells implemented in each model.

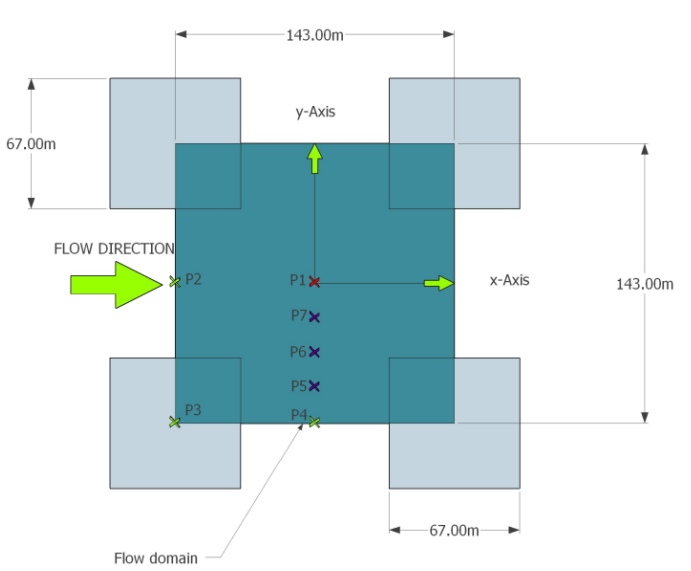

(a) IM-SQuare (IM-SQ)

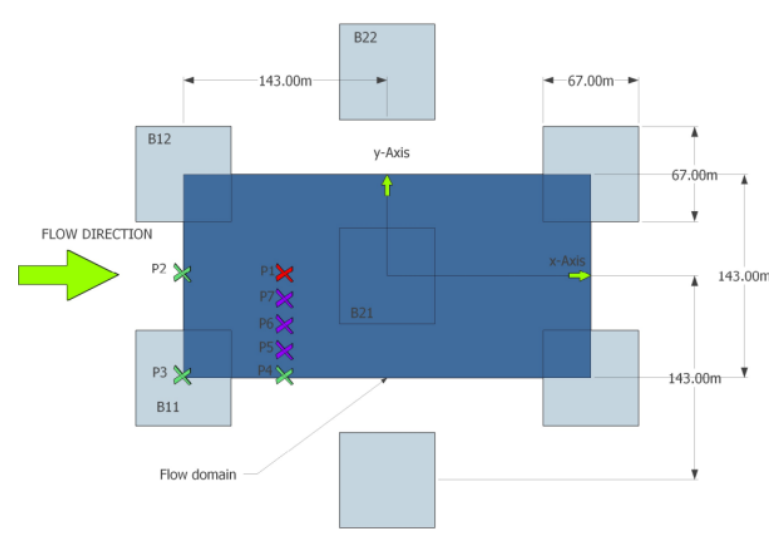

(c) IM-STaGgered (IM-STG)

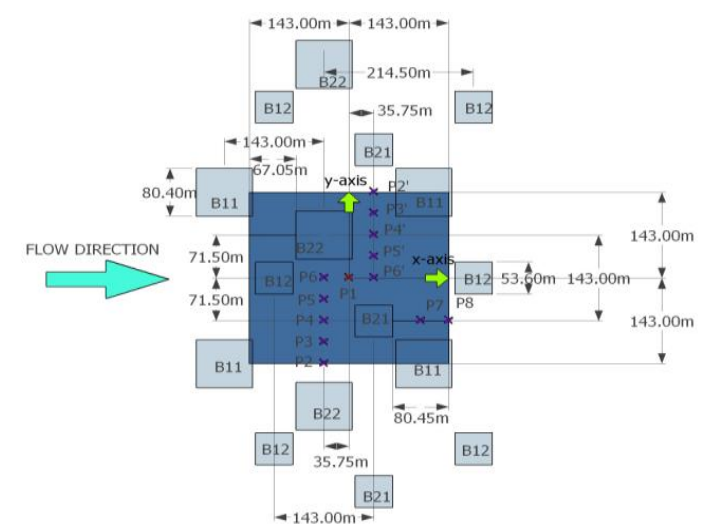

(e) IM-RANdom (IM-RAN)

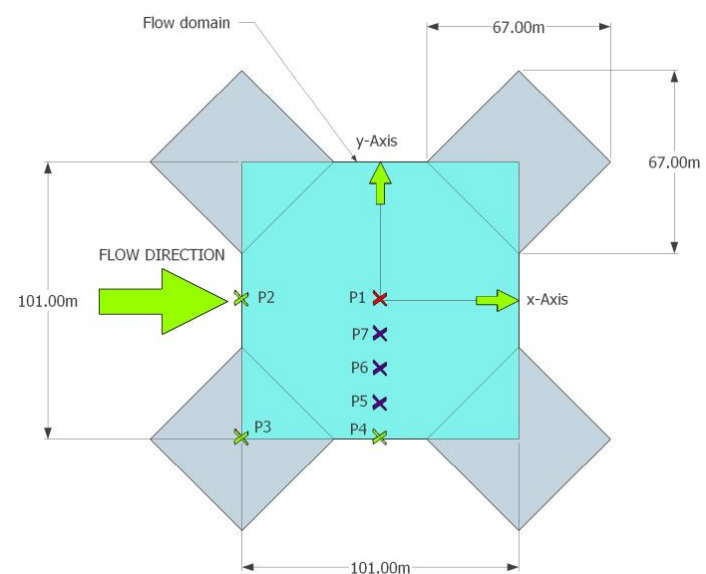

(b) IM-Diamond (IM-D)

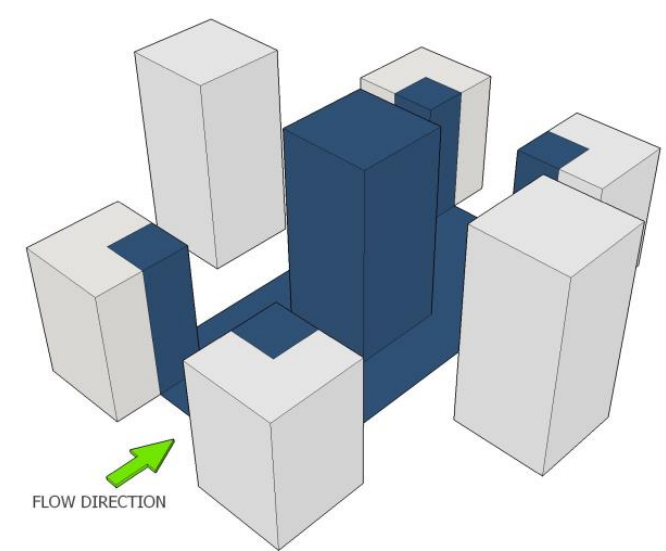

(d) IM-UnEven (IM-UE)

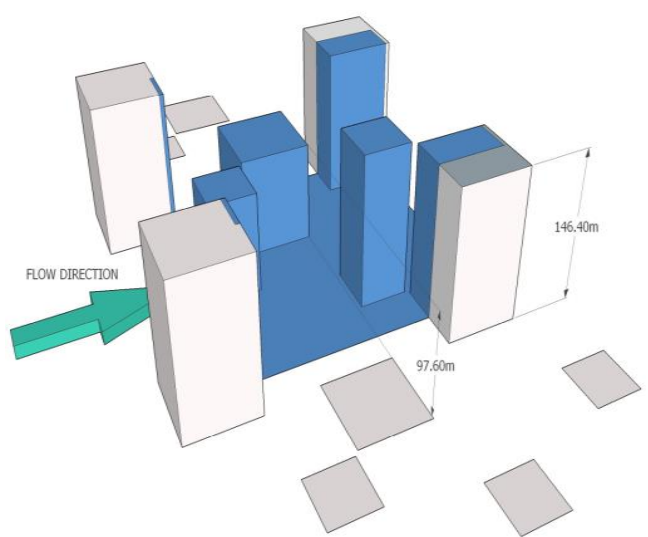

(f) IM-RAN isometric view

Figure 1. Idealised KLCC models (IMs)

Table 2. The number of cells in each model.

\begin{tabular}{cccccccc}
\hline AM & AMF & IM-SQ & IM-D & IM-STG & IM-UE & IM-RAN & C20S \\
\hline $1,201,784$ & $1,922,625$ & 496,384 & 549,442 & 527,796 & 528,426 & 660,543 & 532,786 \\
\hline
\end{tabular}




\section{Case Studies}

The value of wind speed was obtained by analysing the upper air sounding data of Wyoming University. The selected data were captured at Sepang ( $\sim 56 \mathrm{~km}$ southern KLCC), at the nominal ABL height, $1000 \mathrm{~m}$ above ground level $( \pm 100 \mathrm{~m})$, two times per day; at 8 am and 8 pm (local time) over ten years (2004- 2014). Based on this analysis, the free stream velocity was set to $\mathrm{U}_{0}=5 \mathrm{~m} / \mathrm{s}$, its direction was the North-West direction and the whole domain temperature was fixed at $21^{\circ} \mathrm{C}$. These figures agreed well with atmospheric data in the literature [35, 36].

\section{Solution Technique}

As mentioned earlier, OpenFOAM was used [7] to solve the problem. The pressurevelocity coupling was maintained by the PISO algorithm. The solution was initiated with a uniform freestream velocity at all points throughout the domain. For IMs, the simulation continued until a semi-statistical-steady-state was reached. For AM, fifteen turnovers were thought to be sufficient. The time steps, total simulation periods and the number of turnovers considered in the time-averaging process for the different simulations are listed in Table 3.

Table 3. Time parameters for the different models.

\begin{tabular}{ccccccc}
\hline & AM & IM-D & IM-SQ & IM-STG & IM-UE & IM-RAN \\
\hline Time step (s) & 0.02 & 0.002 & 0.01 & 0.04 & 0.02 & 0.02 \\
$\begin{array}{c}\text { Total simulation } \\
\text { period (turnovers) } \\
\begin{array}{c}\text { Averaging period } \\
\text { (turnovers) }\end{array}\end{array}$ & 15 & 74 & 105 & 126 & 126 & 126 \\
\hline
\end{tabular}

\section{Validation of Numerical Setup}

The numerical setup was validated with [23]; a wind tunnel experimental study on flow through urban-like roughness. The model (C20S) involves an array of $\mathbf{2 0} \mathbf{~ m m}$ length sharp-edged Cubes aligned in Staggered arrangement (Figure 1) and subjected to a nominal free stream velocity of $\mathrm{U}_{0}=10 \mathrm{~m} / \mathrm{s}$. The idea behind the validation technique was reproducing the experimental data by a CFD simulation utilising the current numerical setup. The computational domain was confined to one repeating unit $80 \times 40$ $\times 300 \mathrm{~mm}$. The same boundary conditions used in IMs were applied here but the ground and cube walls were treated as smooth walls since no information were available about their roughness heights.

\section{RESULTS AND DISCUSSION}

\section{Validation of Numerical Approach}

As mentioned earlier, the simulations of the IMs continued until the change in time-mean streamwise velocity and turbulence intensity became within 5\% per 10 turnovers. Note that for IM-STG, IM-UE, and IM-RAN the number of turnovers, N, was multiplied by two because their domains contained two rows of buildings. The temporal evolution analysis was conducted to assure the time-independence of the results. The exact statistical steady state (quasi steady state) can only be achieved at much longer times [37]. 
Figure 2 validates the present numerical approach by comparing the mean streamwise velocity and turbulent stresses through C20S measured experimentally by [23] (EXP) with those simulated by the current CFD technique. The points P1- P4 correspond to P0$\mathrm{P} 3$ in [23]. The profiles of the mean streamwise velocity $\left(<\mathrm{u}>/ \mathrm{U}_{0}\right)$ (Figure 2(a) and 2(b)) and streamwise turbulent intensity $\left(\sigma_{\mathrm{u}} / \mathrm{U}_{0}\right)$ (Figure $\left.2(\mathrm{c})\right)$ have shown the best fit with the experimental data. The closest agreement occurs near the cube roof level $(\mathrm{z} \sim \mathrm{H})$. On the other hand, the spanwise and vertical stresses $\left(\sigma_{\mathrm{v}} / \mathrm{U}_{0}\right.$ and $\left.\sigma_{\mathrm{w}} / \mathrm{U}_{0}\right)$ (not shown here) and the vertical turbulent transport $\left(-<\mathrm{u}^{\prime} \mathrm{w}^{\prime}>/ \mathrm{U}_{0}{ }^{2}\right.$ ) (Figure $2(\mathrm{~d})$ ) generally follow the same trend as the experimental measurements but underestimate them. It was thought that a perfect agreement between experimental and CFD data can only be achieved after a very long simulation period which necessitates high computational capabilities beyond those of the resources employed in the current research.

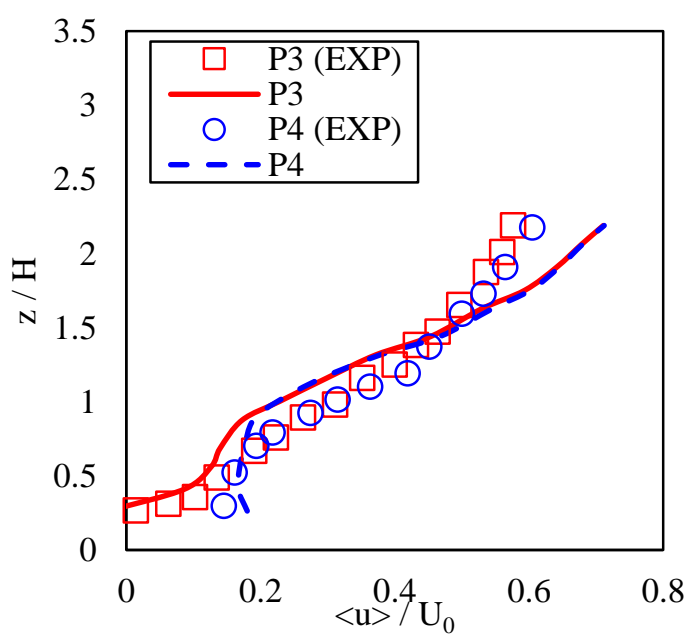

(a)

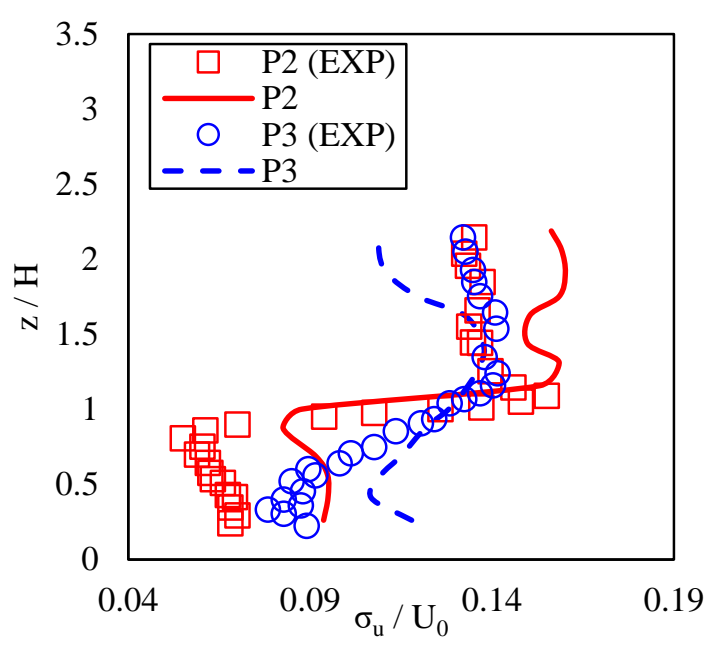

(c)

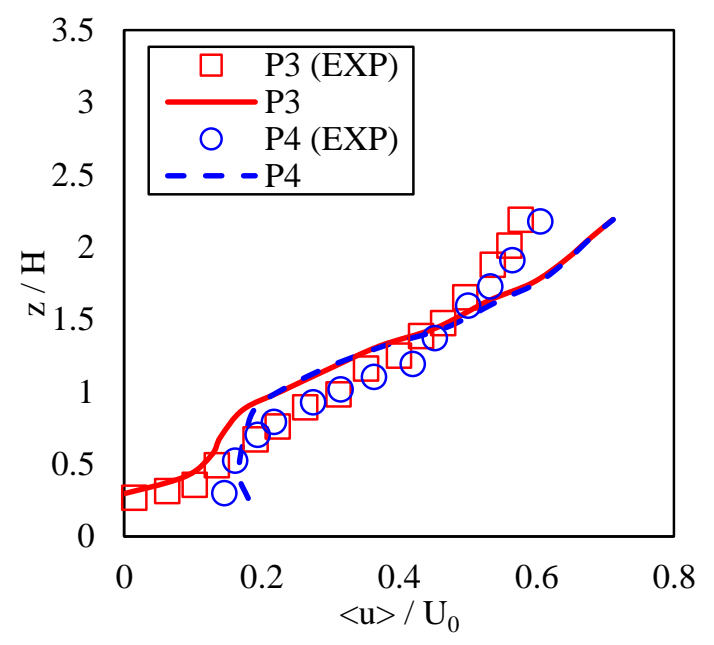

(b)

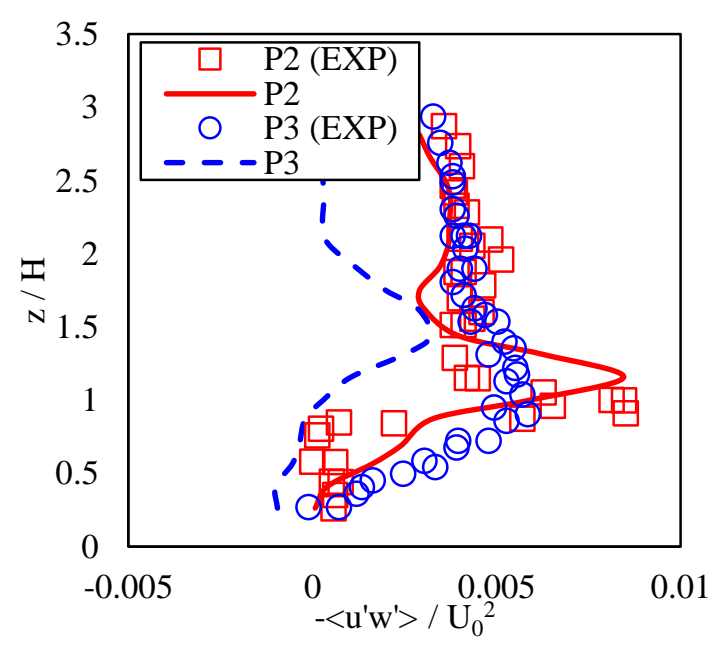

(f)

Figure 2. Validation of numerical setup; comparing the vertical profiles of normalised mean streamwise velocity $\left(<\mathrm{u}>/ \mathrm{U}_{0}\right)$ and turbulent stresses $\left(\sigma_{\mathrm{u}} / \mathrm{U}_{0}\right.$ and $\left.-<\mathrm{u}^{\prime} \mathrm{w}^{\prime}>/ \mathrm{U}_{0}{ }^{2}\right)$ through C20S obtained from the wind tunnel experiments of Castro et al. (2006) with those obtained by the current numerical approach. 


\section{Spatial Averaging}

The mean and turbulent flow parameters within the roughness sublayer are characterised by horizontal inhomogeneity. This imposes the need to select representative sample profiles to compare the models. Although the profile of the plane average values may be considered as the best representative profile, it is difficult to measure experimentally. Two main approaches can be found in the literature; the four-point averaging [38] (4P) and the five-point averaging [39] (5P). For all IMs, except IM-RAN, the four points were numbered as P1-P4 and the five points as P4-P7 and P1. For IM-UE two couples of points were considered around one low- and one high-rise buildings. Two couples of five points (P2-P6 and P2'-P6') plus two separate points (P7 and P8) were adopted in IM-RAN since the four-point average approach was difficult to apply due to its semi-random building designs. Finally, for AM five points (A-E) were included in the averaging process. Those represent five areas of different building densities.

Figure 3 illustrates the spatial averaging techniques applied to the streamwise velocity compared to cross-plane min, max, and average profiles. The comparison in IMs also includes the profile at one single central point (P1). The single point profile greatly deviates from the plane-average profile even at high levels, which ascertains the inappropriateness of such single profiles to describe the flow in idealised models. For IM-SQ (Figure 3(a)) and IM-D (Figure 3(b)), the 5P average is the best replicating the flow characteristics in the urban canopy layer $(\mathrm{z} / \mathrm{H}<1)$ while the remainder of the surface layer is best represented by the 4P average [38]. Thus a (Mix) of both averages is going to be used for these two models thereafter. On the other hand, the 5P (10P for IM-UE) average fits the whole surface layer in both IM-STG (Figure 3(c)) and IM-UE (Figure 3(d)). Another (Mix) was utilised for IM-RAN which elaborates P2-P8 for $\mathrm{z} / \mathrm{H}<1.35$ and (P2-P6 and P2'-P6') for the rest of the layer. Despite the large velocity diversity in AM, the five profiles selected to represent the model still resemble the trend of the planeaverage profile and coincide with it beyond $\mathrm{z} / \mathrm{H}>3.3$, Figure 3(f).

\section{From IMs towards AM}

This section compares the different idealised models (IMs) with the actual city model (AM) to address the effectiveness of each model in producing actual urban flow characteristics. Figures 4 and 5 compare IMs with AM for mean and turbulent parameters, respectively. A brief look upon figures declares the wide thickness of AM surface layer compared to IMs. The surface layer, defined in terms of mean streamwise velocity, in case of AM ends at an altitude of $\mathrm{z} / \mathrm{H} \sim 9$ which is double that in the closest similar IM. Both IM-SQ and IM-STG give very similar mean streamwise velocity profiles which are rather far from AM (Figure 4(a)). The IMs' profiles start to improve from IM-UE due to building height variability. IM-RAN shows the nearest profile to AM even though it comprises the same heights as in IM-UE which indicates the importance of building size and spacing variability. IM-D develops the narrowest surface layer since the streamlined diamond shape provides the least interaction (resistance) to the flow. Just like AM, IMRAN produces minimal vertical velocity oscillations (Figure 4(b)) since the random arrangement breaks the large vortical structures behind buildings. Going to the turbulent flow parameters (Figure 5), IM-RAN is still the best idealised model depicting the actual model data of streamwise stress (Figure 5(a)), vertical stress (Figure 5(c)) and vertical transport (Figure 5(d)). Both IM-SQ and IM-STG give similar stress but far from AM, turbulent profiles. The spanwise turbulent transport $\left(\left\langle u^{\prime} v^{\prime}\right\rangle\right.$ ) (Figure 5(b)) exhibits random trends that can hardly be used to evaluate the model proficiency, however, both 
IM-UE and IM-RAN provide close absolute values to AM with the second extending to higher altitudes.

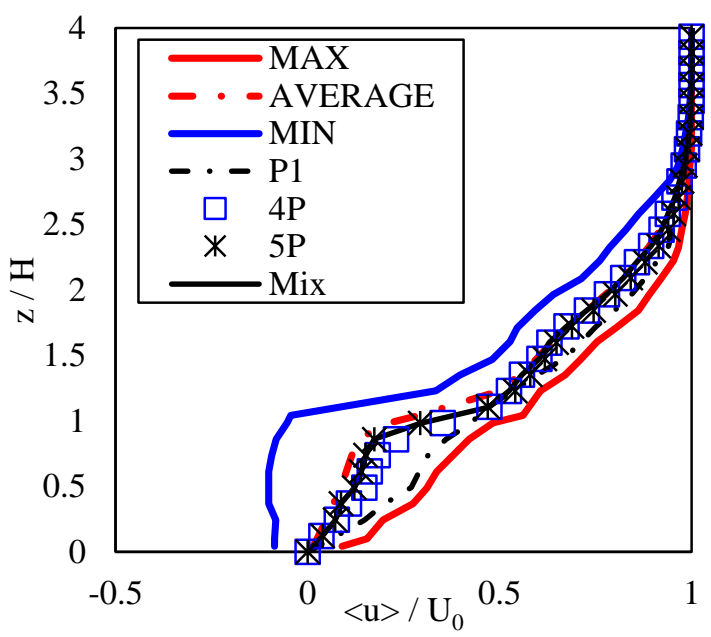

(a) IM-SQ

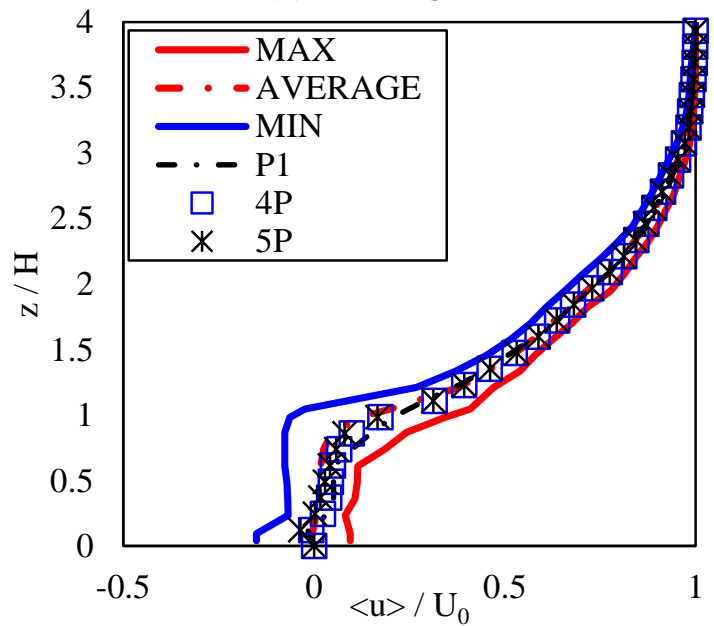

(c) IM-STG

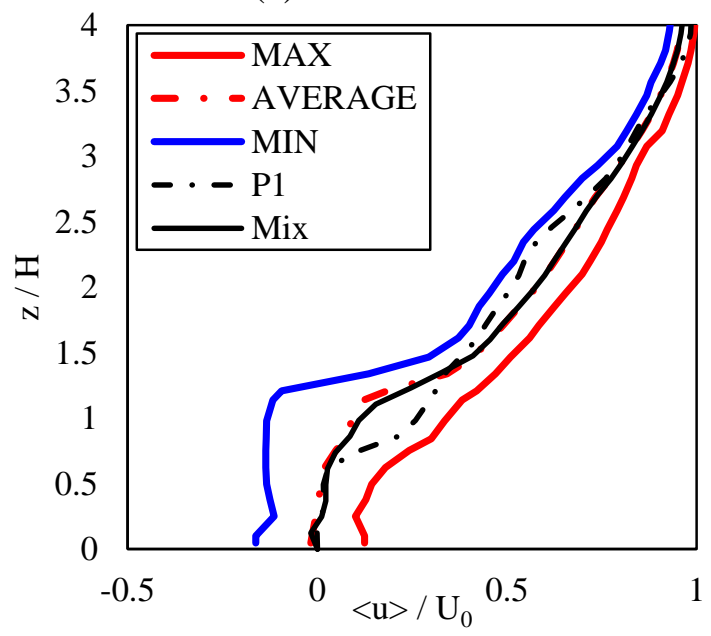

(e) IM-RAN

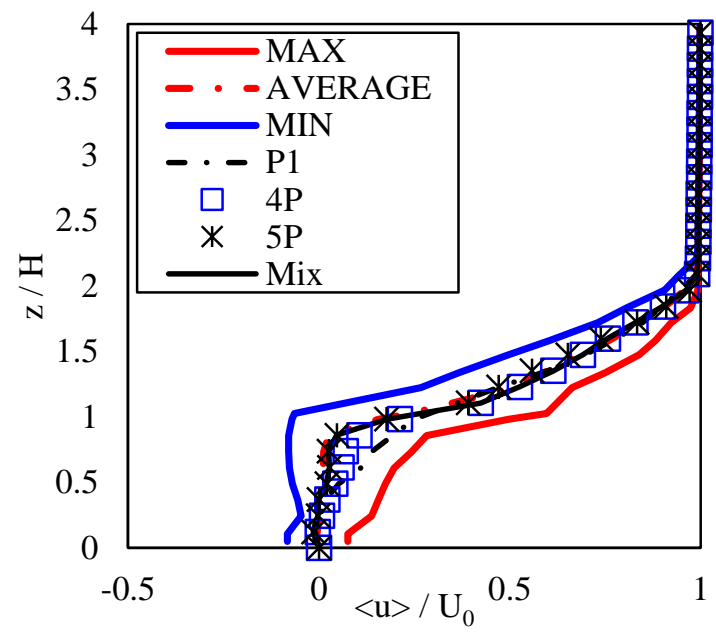

(b) IM-D

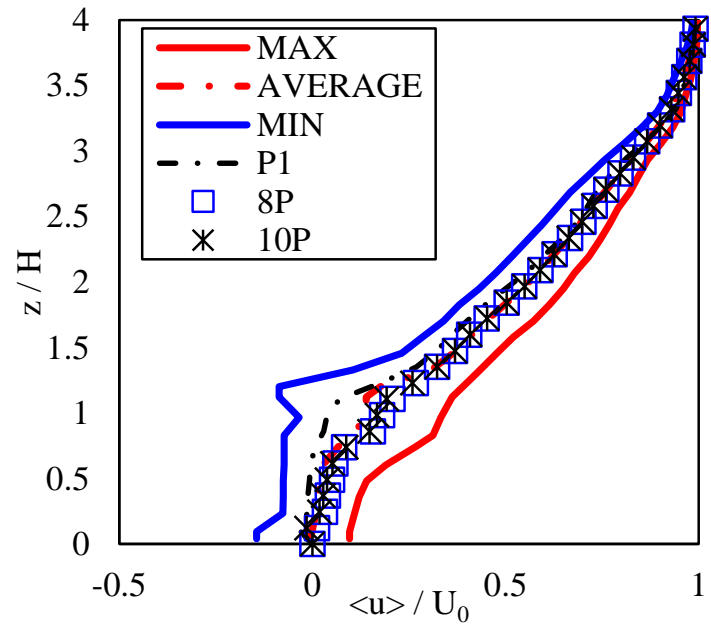

(d) IM-UE

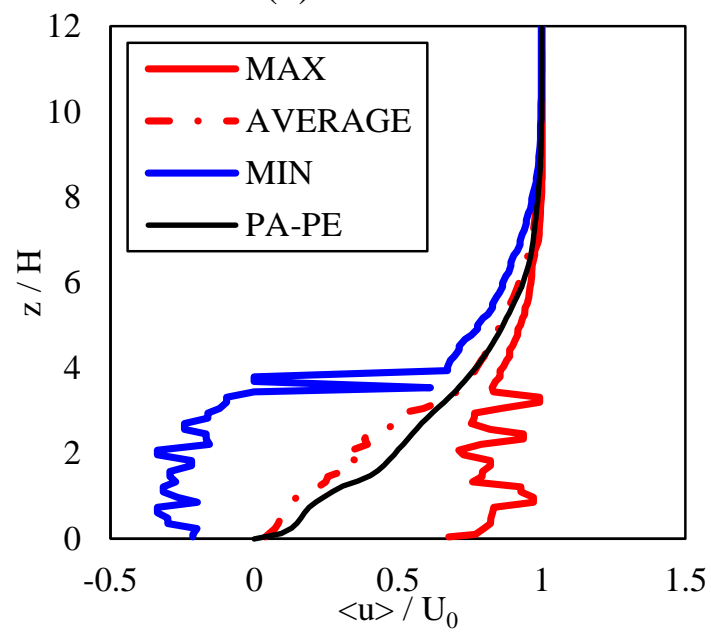

(f) $\mathrm{AM}$

Figure 3. Comparison of the spatial averaging techniques with the vertical profiles of maximum, minimum, and average of streamwise velocity. 


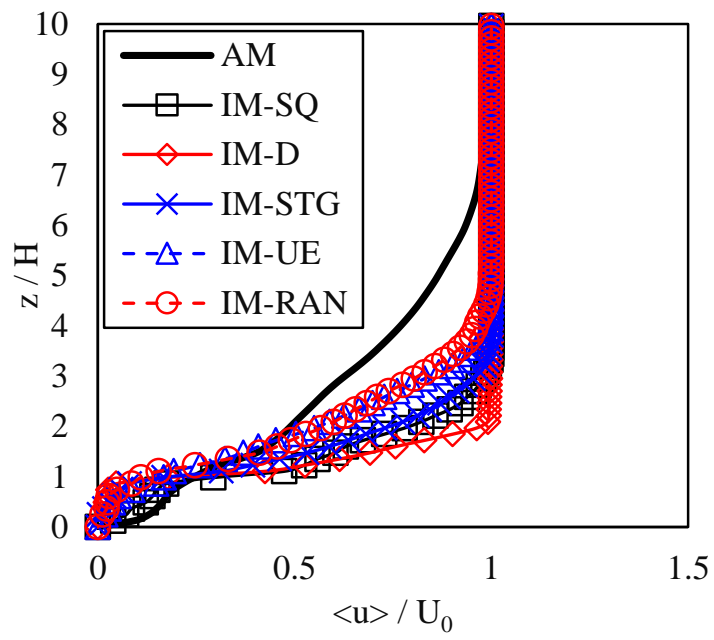

(a)

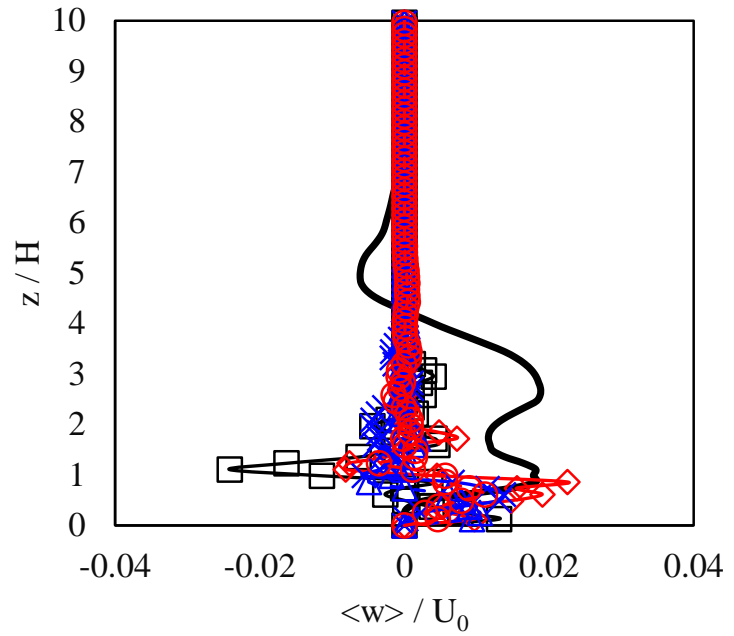

(b)

Figure 4. Comparison of normalised mean velocity components $\left(<\mathrm{u}>/ \mathrm{U}_{0}\right.$ and $<\mathrm{w}$ $\left.>/ \mathrm{U}_{0}\right)$ in IMs with those in AM.

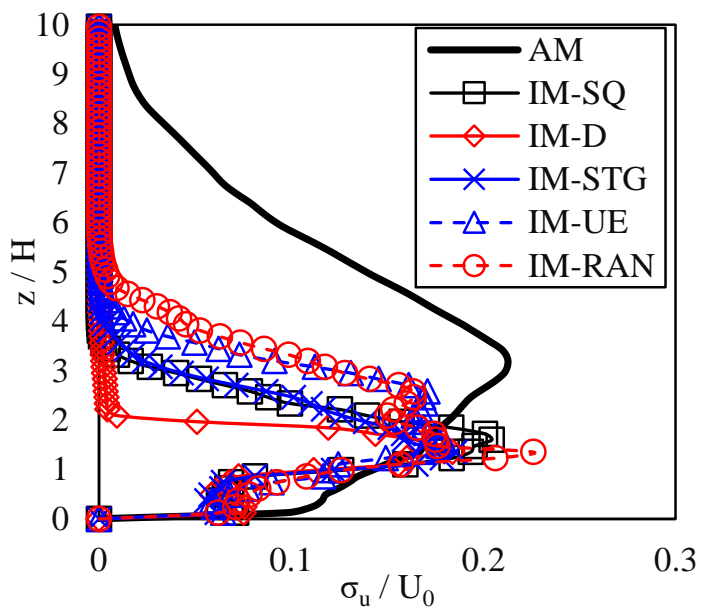

(a)

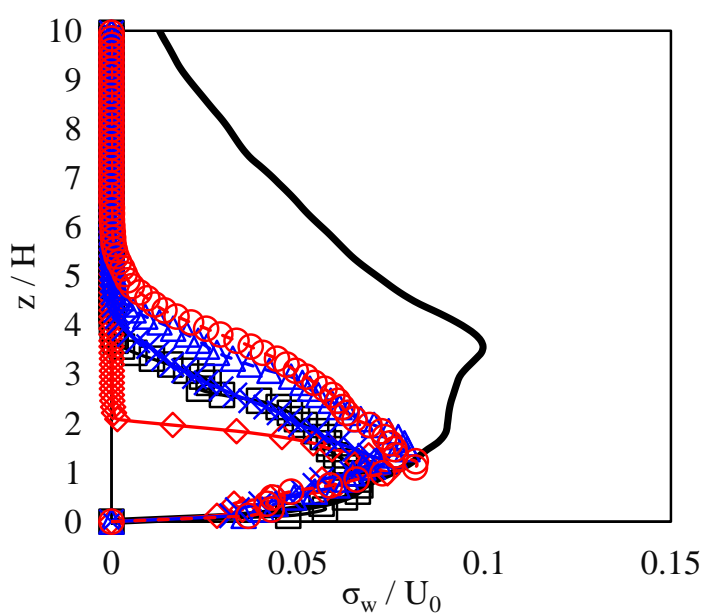

(e)

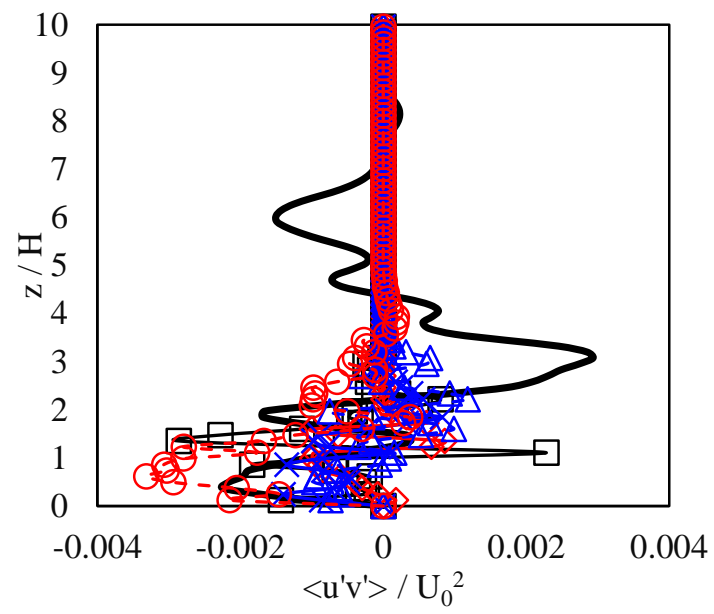

(b)

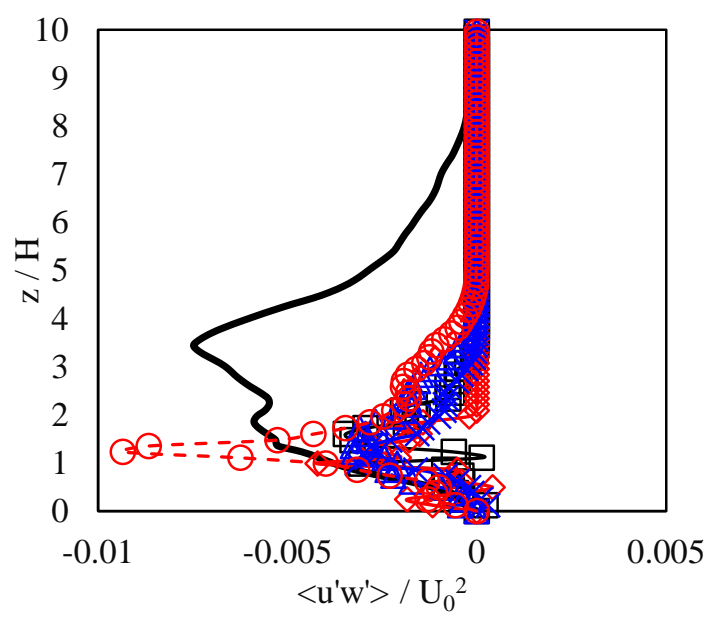

(f)

Figure 5. Comparison of normalised turbulent stresses $\left(\sigma_{\mathrm{u}} / \mathrm{U}_{0}, \sigma_{\mathrm{v}} / \mathrm{U}_{0}, \sigma_{\mathrm{w}} / \mathrm{U}_{0},<\mathrm{u}^{\prime} \mathrm{v}^{\prime}\right.$ $>/ \mathrm{U}_{0}^{2},<\mathrm{v}^{\prime} \mathrm{w}^{\prime}>/ \mathrm{U}_{0}^{2}$ and $\left.<\mathrm{u}^{\prime} \mathrm{w}^{\prime}>/ \mathrm{U}_{0}{ }^{2}\right)$ in IMs with those in AM. 
The present results match with the previous findings that the morphological complexity of genuine cities implies the disparity of flow structure as compared to idealised models. Many authors (e.g. [24]) concluded that building height variability leads to a different (usually better) pollutant dispersion. Zhang et al. [40] delivered few examples from the literature for this fact. A single high-rise building in a street canyon drastically alters the flow structure in its vicinity. The alignment of high-rise buildings in complex urban environments restricts the air ventilation and yields pollutant concentration. Zhang et al. demonstrated also that uneven building layout generally intensifies turbulence and enhances pollutant dispersion. The non-uniformity in street lengths can be another reason for the large discrepancy between the actual and idealised models [41]. The present results record the failure of the idealised urban models to represent actual air flow through cities.

\section{Vertical profile correction}

A similarity between vertical profiles of $\langle\mathrm{u}\rangle, \sigma_{\mathrm{u}}, \sigma_{\mathrm{v}}, \sigma_{\mathrm{w}}$ and $\left\langle\mathrm{u}^{\prime} \mathrm{w}^{\prime}>\right.$ for IMs and AM can be noticed in Figure 4 and 5. It is hypothesised that the profiles of IMs are "heightcontracted" versions of AM profiles. Therefore, the correction process targets the height rather than the flow parameters themselves. The correction equation is given by

$$
\left(\frac{Z}{H}\right)_{\text {corrected }}=A\left(\frac{Z}{H}\right)^{B}
$$

A and B were chosen such that the curves fit in the inertial sublayer rather than in the whole surface layer. As mentioned earlier, IM-RAN was the only model subjected to correction due to its high similarity with AM. The values calculated for A and B are listed in Table 4. Finally, the grid-dependence analysis held between AM and AMF demonstrated a maximum deviation of less than $5 \%$ between the two models for all the parameters tested which validates the integrity of the results.

Table 4. Correction coefficients for IM-RAN height.

\begin{tabular}{cccccc}
\hline & $<\mathrm{u}>/ \mathrm{U}_{0}$ & $\sigma_{\mathrm{u}} / \mathrm{U}_{0}$ & $\sigma_{\mathrm{v}} / \mathrm{U}_{0}$ & $\sigma_{\mathrm{w}} / \mathrm{U}_{0}$ & $\left\langle\mathrm{u}^{\prime} \mathrm{w}^{\prime}>/ \mathrm{U}_{0}^{2}\right.$ \\
\hline $\mathrm{A}$ & 0.8314 & 1.2409 & 1.1789 & 2.4966 & 2.2998 \\
\hline B & 1.5282 & 1.3087 & 1.4086 & 0.912 & 0.861 \\
\hline
\end{tabular}

\section{CONCLUSIONS}

Although a large part of the experimental and CFD research on urban wind flow is held on idealised models, the ability to extrapolate the results to actual cities is yet uncertain. The objective of this study is to correlate the mean and turbulent flow parameters of idealised models with those of actual urban environment. An LES was conducted for wind flow through an actual model for KLCC (AM) and a group of idealised models (IMs) with the same average dimensions and building-packing-density. The numerical setup was validated with experimental data from the literature. Two spatial averaging techniques have been examined in IMs; the five-point and four-point techniques. The conclusions are highlighted as following: 
- The five-point spatial average proved to be more representative of the data inside the urban canopy layer and the four-point technique in the roughness and inertial sublayers; a mix of both averages is recommended.

- IM-RAN was found to show the closest profiles, in terms of both trend and values, to AM. Nonetheless, the surface layer thickness in case of IM-RAN is half that of $\mathrm{AM}$ and the peak values were rather different between the two models.

- The results manifested a significant role played by the building size and spacing variability in determining the flow structure through urban areas and the urban boundary layer height which coincides with previous findings.

- Finally, a correction method was proposed to extrapolate the vertical profiles of idealized models to actual cities.

Much work is still needed to develop an idealised model that can be used to precisely mimic the flow features in actual cities, even with correction. This is thought to be the first step on the way to standardise modern city planning.

\section{ACKNOWLEDGMENTS}

The authors would like to thank Universiti Kebangsaan Malaysia for the Research University Grants (DIP-2015-006)) and the Ministry of Education for the Exploratory Research Grant (ERGS/1/2013/TK01/UKM/03/2).

\section{REFERENCES}

[1] Tahseen TA, Rahman MM, Ishak M. Effect of tube spacing, fin density and Reynolds number on overall heat transfer rate for in-line configuration. International Journal of Automotive and Mechanical Engineering. 2015;12:306575.

[2] Al-Faruk A, Sharifian AS. Effects of flow parameters on the performance of vertical axis swirling type Savonius wind turbine. International Journal of Automotive and Mechanical Engineering. 2015;12:2929-43.

[3] Wahhad AM, Adam NM, Sapuan SM. Comparison of numerical simulation and experimental study on indoor air quality of air-conditioned office building in desert climate. International Journal of Automotive and Mechanical Engineering. 2015;12:3109-24.

[4] Baha NZ, Osman SA. Extreme Wind Effects on Roof Structures of Low Rise Buildings. Jurnal Kejuruteraan. 2017;2017:31-6.

[5] Rahman MAA, Thiagarajan KP. Experiments on vortex-induced vibration of a vertical cylindrical structure: effect of low aspect ratio. International Journal of Automotive and Mechanical Engineering. 2015;11:2515-30.

[6] Lotfy ER, Harun Z. Effect of atmospheric boundary layer stability on the inclination angle of turbulence coherent structures. Environmental Fluid Mechanics.1-23.

[7] Flores F, Garreaud R, Muñoz RC. CFD simulations of turbulent buoyant atmospheric flows over complex geometry: Solver development in Open FOAM. Computers \& Fluids. 2013;82:1-13.

[8] Kakosimos KE, Assael MJ. Application of Detached Eddy Simulation to neighbourhood scale gases atmospheric dispersion modelling. Journal of Hazardous Materials. 2013;261:653-68. 
[9] Kikumoto H, Ooka R. A numerical study of air pollutant dispersion with bimolecular chemical reactions in an urban street canyon using large-eddy simulation. Atmospheric Environment. 2012;54:456-64.

[10] Liu J, Srebric J, Yu N. Numerical simulation of convective heat transfer coefficients at the external surfaces of building arrays immersed in a turbulent boundary layer. International Journal of Heat and Mass Transfer. 2013;61:20925.

[11] Mavroidis I, Andronopoulos S, Bartzis JG. Computational simulation of the residence of air pollutants in the wake of a 3-dimensional cubical building. The effect of atmospheric stability. Atmospheric Environment. 2012;63:189-202.

[12] Moonen P, Dorer V, Carmeliet J. Effect of flow unsteadiness on the mean wind flow pattern in an idealized urban environment. Journal of Wind Engineering and Industrial Aerodynamics. 2012;104:389-96.

[13] Rusdin A. Computation of turbulent flow around a square block with standard and modified $\mathrm{k}-\varepsilon$ turbulence models. International Journal of Automotive \& Mechanical Engineering. 2017;14:3938-53.

[14] Kono T, Tamura T, Ashie Y. Numerical investigations of mean winds within canopies of regularly arrayed cubical buildings under neutral stability conditions. Boundary-Layer Meteorology. 2010;134:131-55.

[15] Takahashi K, Yoshida H, Tanaka Y, Aotake N, Wang F. Measurement of thermal environment in Kyoto city and its prediction by CFD simulation. Energy and Buildings. 2004;36:771-9.

[16] Nozu T, Tamura T, Okuda Y, Sanada S. LES of the flow and building wall pressures in the center of Tokyo. Journal of Wind Engineering and Industrial Aerodynamics. 2008;96:1762-73.

[17] Xie Z-T, Castro IP. Large-eddy simulation for flow and dispersion in urban streets. Atmospheric Environment. 2009;43:2174-85.

[18] Gousseau P, Blocken B, Stathopoulos T, Van Heijst GJF. CFD simulation of nearfield pollutant dispersion on a high-resolution grid: a case study by LES and RANS for a building group in downtown Montreal. Atmospheric Environment. 2011;45:428-38.

[19] Liu YS, Cui GX, Wang ZS, Zhang ZS. Large eddy simulation of wind field and pollutant dispersion in downtown Macao. Atmospheric Environment. 2011;45:2849-59.

[20] Wyszogrodzki AA, Miao S, Chen F. Evaluation of the coupling between mesoscale-WRF and LES-EULAG models for simulating fine-scale urban dispersion. Atmospheric Research. 2012;118:324-45.

[21] Liu YS, Miao SG, Zhang CL, Cui GX, Zhang ZS. Study on micro-atmospheric environment by coupling large eddy simulation with mesoscale model. Journal of Wind Engineering and Industrial Aerodynamics. 2012;107:106-17.

[22] Harun Z, Reda E, Abdullah S. Large eddy simulation of the air flow through Kuala Lumpur City Center. Proceedings of the 1st Thermal and Fluids Engineering Summer Conference, TFESC-12015.

[23] Castro IP, Cheng H, Reynolds R. Turbulence over urban-type roughness: deductions from wind-tunnel measurements. Boundary-Layer Meteorology. 2006;118:109-31.

[24] Hang J, Li Y, Sandberg M, Buccolieri R, Di Sabatino S. The influence of building height variability on pollutant dispersion and pedestrian ventilation in idealized high-rise urban areas. Building and Environment. 2012;56:346-60. 
[25] Cheng H, Castro IP. Near wall flow over urban-like roughness. Boundary-Layer Meteorology. 2002;104:229-59.

[26] Sun L, Nottrott A, Kleissl J. Effect of hilly urban morphology on dispersion in the urban boundary layer. Building and Environment. 2012;48:195-205.

[27] Stull RB. An introduction to boundary layer meteorology: Springer Science \& Business Media; 1988.

[28] Meneveau C, Lund TS, Cabot WH. A Lagrangian dynamic subgrid-scale model of turbulence. Journal of Fluid Mechanics. 1996;319:353-85.

[29] Zhou B, Chow FK. Turbulence modeling for the stable atmospheric boundary layer and implications for wind energy. Flow, Turbulence and Combustion. 2012;88:255-77.

[30] Pieterse JE, Harms TM. CFD investigation of the atmospheric boundary layer under different thermal stability conditions. Journal of Wind Engineering and Industrial Aerodynamics. 2013;121:82-97.

[31] Qu Y, Milliez M, Musson-Genon L, Carissimo B. Numerical study of the thermal effects of buildings on low-speed airflow taking into account 3D atmospheric radiation in urban canopy. Journal of Wind Engineering and Industrial Aerodynamics. 2012;104:474-83.

[32] Kastner-Klein P, Rotach MW. Mean flow and turbulence characteristics in an urban roughness sublayer. Boundary-Layer Meteorology. 2004;111:55-84.

[33] Franke J, Hellsten A, Schlünzen H, Carissimo B. Best practice guideline for the CFD simulation of flows in the urban environment. COST Action 732. Quality Assurance And Improvement of Microscale Meteorological Models; 2007.

[34] Razak AA, Hagishima A, Ikegaya N, Tanimoto J. Analysis of airflow over building arrays for assessment of urban wind environment. Building and Environment. 2013;59:56-65.

[35] Harun Z, Reda E, Zulkifli R. Buoyancy effect on atmospheric surface layer: measurements from the East Coast of Malaysia. The 15th Asian Congress of Fluid Mechanics; 2016.

[36] Latif MT, Dominick D, Ahamad F, Khan MF, Juneng L, Hamzah FM, et al. Long term assessment of air quality from a background station on the Malaysian Peninsula. Science of the total environment. 2014;482:336-48.

[37] Coceal O, Thomas TG, Castro IP, Belcher SE. Mean flow and turbulence statistics over groups of urban-like cubical obstacles. Boundary-Layer Meteorology. 2006;121:491-519.

[38] Cheng H, Castro IP. Near wall flow over urban-like roughness. Boundary-Layer Meteorology. 2002;104:229-59.

[39] Macdonald RW. Modelling the mean velocity profile in the urban canopy layer. Boundary-Layer Meteorology. 2000;97:25-45.

[40] Zhang Y, Gu Z, Wang Z, Cheng Y, Lee FSC. Advances in the fine scale simulation of urban wind environment. Indoor and Built Environment. 2013;22:332-6.

[41] Kitous S, Bensalem R, Adolphe L. Airflow patterns within a complex urban topography under hot and dry climate in the Algerian Sahara. Building and Environment. 2012;56:162-75. 